\title{
$\beta$ III-Tubulin Structural Domains Regulate Mitochondrial Network Architecture in an Isotype-Specific Manner
}

\author{
Amelia L. Parker 1,2,3,+, Wee Siang Teo ${ }^{1,2,3}$, Simon Brayford ${ }^{1,2,3}$, Ullhas K. Moorthi ${ }^{4}$, Senthil Arumugam ${ }^{4,5}$, \\ Charles Ferguson ${ }^{6}$, Robert G. Parton ${ }^{6,7}$ (D), Joshua A. McCarroll 1,2,3,* and Maria Kavallaris 1,2,3,*(D)
}

1 Children's Cancer Institute, Lowy Cancer Research Centre, UNSW Sydney, Sydney, NSW 2052, Australia; am.parker@garvan.org.au (A.L.P.); wee.teo@glytherix.com (W.S.T.); sbrayford@ccia.org.au (S.B.)

2 School of Women's and Children's Health, Faculty of Medicine and Health, UNSW Sydney, Sydney, NSW 2052, Australia

3 Australian Centre for NanoMedicine, UNSW Sydney, Sydney, NSW 2052, Australia

4 Monash Biomedicine Discovery Institute, Faculty of Medicine, Nursing and Health Sciences, Monash University, Clayton, Melbourne, VIC 3800, Australia; ullhas.moorthi@monash.edu (U.K.M.); senthil.arumugam@monash.edu (S.A.)

5 European Molecular Biological Laboratory Australia (EMBL Australia), Monash University, Clayton, Melbourne, VIC 3800, Australia

6 Institute for Molecular Bioscience, University of Queensland, Brisbane, QLD 4072, Australia; c.ferguson@imb.uq.edu.au (C.F.); r.parton@imb.uq.edu.au (R.G.P.)

7 Centre for Microscopy and Microanalysis, University of Queensland, Brisbane, QLD 4072, Australia

* Correspondence: jmccarroll@ccia.org.au (J.A.M.); m.kavallaris@ccia.unsw.edu.au (M.K.)

† Current address: Garvan Institute of Medical Research, Darlinghurst, NSW 2010, Australia.

check for

updates

Citation: Parker, A.L.; Teo, W.S.;

Brayford, S.; Moorthi, U.K.;

Arumugam, S.; Ferguson, C.;

Parton, R.G.; McCarroll, J.A.;

Kavallaris, M. $\beta$ III-Tubulin Structural

Domains Regulate Mitochondrial

Network Architecture in an

Isotype-Specific Manner. Cells 2022,

11, 776. https://doi.org/10.3390/

cells11050776

Academic Editor: Bin Wu

Received: 20 January 2022

Accepted: 20 February 2022

Published: 23 February 2022

Publisher's Note: MDPI stays neutral with regard to jurisdictional claims in published maps and institutional affiliations.

Copyright: (c) 2022 by the authors. Licensee MDPI, Basel, Switzerland. This article is an open access article distributed under the terms and conditions of the Creative Commons Attribution (CC BY) license (https:// creativecommons.org/licenses/by/ $4.0 /)$.

\begin{abstract}
III-tubulin is a neuronal microtubule protein that is aberrantly expressed in epithelial cancers. The microtubule network is implicated in regulating the architecture and dynamics of the mitochondrial network, although the isotype-specific role for $\beta$-tubulin proteins that constitute this microtubule network remains unclear. High-resolution electron microscopy revealed that manipulation of $\beta$ III-tubulin expression levels impacts the volume and shape of mitochondria. Analysis of the structural domains of the protein identifies that the C-terminal tail of $\beta$ III-tubulin, which distinguishes this protein from other $\beta$-tubulin isotypes, significantly contributes to the isotype-specific effects of $\beta$ III-tubulin on mitochondrial architecture. Mass spectrometry analysis of protein-protein interactions with $\beta$-tubulin isotypes identifies that $\beta$ III-tubulin specifically interacts with regulators of mitochondrial dynamics that may mediate these functional effects. Advanced quantitative dynamic lattice light sheet imaging of the mitochondrial network reveals that $\beta$ III-tubulin promotes a more dynamic and extended reticular mitochondrial network, and regulates mitochondrial volume. A regulatory role for the $\beta$ III-tubulin C-terminal tail in mitochondrial network dynamics and architecture has widespread implications for the maintenance of mitochondrial homeostasis in health and disease.
\end{abstract}

Keywords: tubulin isotype; mitochondria; microtubules; carboxy-terminal tail

\section{Introduction}

Microtubules are fundamental components of all eukaryotic cells. In humans, microtubules are composed of mixed combinations of eight $\alpha$-tubulin isotypes and seven $\beta$-tubulin isotypes [1]. $\beta$ III-tubulin has a highly specific tissue distribution, and is expressed in neurons and testicular Sertoli cells in adults. It is also aberrantly expressed in epithelial cancers derived from tissues that normally lack or have very low expression of $\beta$ III-tubulin, including non-small cell lung cancer [2]. Despite recent advances identifying that $\beta$-tubulin isotypes have specific functions as regulators of microtubule dynamics, metabolism and chemosensitivity [3-6], the distinct isotype-specific roles of $\beta$-tubulin isotypes remain incompletely characterized. 
The architecture and dynamics of the mitochondrial network have far-reaching impacts on a broad range of fundamental cellular functions in health and disease. Microtubules are involved in mitochondrial localization and trafficking [7-10], and tubulin proteins have also been associated with the mitochondrial quality control machinery [11-14], although the contribution of individual $\beta$-tubulin isotypes on mitochondrial dynamics remains unclear. Mitochondrial trafficking along microtubules is highly regulated to direct mitochondria to sites of high metabolic demand [9,15-17]. This interaction between microtubules and mitochondria is a reciprocal relationship, with microtubules involved in mitochondrial trafficking and degradation, and these processes influencing microtubule stability and tubulin degradation in return [12]. The role of specific tubulin isotypes in regulating mitochondrial trafficking on microtubules is poorly understood.

The $\beta$-tubulin isotypes that form microtubules share a high degree of sequence similarity, and are distinguished from one another largely by the sequence of their C-terminal tails that extend outwards from the wall of the microtubule. Protein-protein interactions with these isotype-specific sequences are thought to confer diverse and unique functionality to the different $\beta$-tubulin isotypes and explain their tissue specific distributions [6]. Growing associative evidence points to an isotype-specific role for $\beta$-tubulin proteins in mitochondrial trafficking and function, where the composition of tubulin isotypes within cells collectively and combinatorially regulates microtubule-dependent functions [18,19]. Recent studies have indicated that the posttranslational modifications on microtubule subsets can regulate ER localization as well as that of lysosomes and vesicles through specific protein-protein interactions [20]. In addition to post-translational modifications, different $\beta$-tubulin isotypes also confer heterogeneity to the microtubule network to collectively constitute the tubulin code. The $\beta$-tubulin isotypes differentially affect microtubule dynamics [3,21-23], which regulates kinesin-independent mitochondrial trafficking [24-26] by hitherto undefined mechanisms.

Similarly, both the $\beta$-tubulin body and tail regions interact with kinesin proteins to regulate kinesin processivity [27-30], thereby affecting kinesin-dependent trafficking [31,32]. $\beta$-tubulin proteins also interact with the mitochondrially localized voltage-dependent anion channel to regulate channel conductance in an isotype-specific manner [33-35]. In these respects, the $\beta$ III-tubulin isotype displays distinct characteristics compared with other $\beta$-tubulin isotypes. $\beta$ III-tubulin, and particularly its $C$-terminal tail domain, promotes more dynamic microtubules [3,23], and orchestrates the collective behavior of the microtubule network [3], significantly blocks the mitochondrial voltage-dependent anion channel [33], and has a greater inhibitory effect on kinesin- 1 processivity than other $\beta$-tubulin isotypes [30]. $\beta$ III-tubulin is also enriched in mitochondrial membranes [7,34,36-38], although it is not clear if $\beta$ III-tubulin interacts directly with mitochondrial membranes or through linker proteins $[7,9,34,36,39]$. These functional effects of $\beta$ III-tubulin on the regulators of mitochondrial trafficking are re-enforced by clinical observations that congenital mutations within helix 12 adjacent to the $\beta$ III-tubulin C-terminal tail result in neurodevelopmental defects associated with abnormal mitochondrial trafficking, and phenocopy those caused by kinesin mutations [40-43]. However, the role of $\beta$ III-tubulin structural domains in the wild-type protein remains unclear.

Our previous work identified a role for $\beta$ III-tubulin in promoting central carbon metabolism flexibility by enabling cancer cells to rapidly switch between oxidative phosphorylation and glycolysis in response to nutrient starvation independently of microtubule architecture [4]. This warrants further investigation of how this $\beta$-tubulin isotype affects mitochondrial architecture and, therefore, function. However, the role of $\beta$ III-tubulin in mitochondrial dynamics, and the importance of its structural domains in regulating mitochondrial network architecture, remain unclear.

This study used orthogonal high-resolution static and dynamic imaging approaches to identify an isotype-specific role for $\beta$ III-tubulin and its structural domains in regulating mitochondrial localization and architecture, thereby contributing to our understanding of the tubulin code. 


\section{Materials and Methods}

\subsection{Cell Culture}

The human non-small cell lung cancer (NSCLC) cell lines NCI-H460 and A549 cells were cultured and validated as described previously [4,5]. All parental, control and knockdown cell lines were validated by STR profiling (ATCC). Control non-silencing shRNA and $\beta$ III-tubulin shRNA expressing NCI-H460 and A549 clones were cultured and validated as described previously $[4,5]$. $\beta$ III-tubulin is a minor $\beta$-tubulin isotype, and we have previously validated that suppression of $\beta$ III-tubulin expression in these cells does not alter the expression of other $\beta$-tubulin isotypes $[5,44]$. Gene-edited NCI-H460 cell lines were generated and cultured as described previously [3]. Two sets of gene-edited NCI-H460 cells were generated, each set containing clones with matched expression of the modified $\beta$ III-tubulin from the TUBB3 locus as previously described [3]. Importantly, the expression of other $\beta$-tubulin isotypes was not altered by the expression of modified $\beta$ III-tubulin proteins from the edited TUBB3 gene [3]. Gene editing of the TUBB3 locus in the gene-edited clones was confirmed by genomic sequencing (Sanger sequencing, Garvan Molecular Genetics, Garvan Institute, Australia) across the edited site. All cell lines were regularly screened to ensure the absence of mycoplasma contamination using the MycoAlert MycoPlasma Detection Kit (Lonza, Switzerland).

\subsection{Mitochondrial Network Immunofluorescence}

NCI-H460 and A549 cells cultured on poly-D-lysine-coated chamber slides (ThermoFisher Scientific, Waltham, MA, USA) were fixed in $4 \%$ paraformaldehyde and permeabilized in $0.1 \%$ Triton X-100, blocked in 10\% FCS/PBS at room temperature followed by immunostaining with GRP75 antibody (JG1, Abcam, Cambridge, UK; 1:500) overnight at $4^{\circ} \mathrm{C}$. Cells were washed three times with PBS and incubated with Alexa-fluor568-conjugated secondary antibody (1:500) for one hour at room temperature. Slides were then washed (PBS) and mounted in DAPI-containing mounting media (Vectashield, Vector Labs, Burlingame, CA, USA). Cells were imaged using a Leica SP8 confocal microscope.

For quantification of mitochondrial distribution across the entire cytoplasm, the GRP75 staining intensity was measured radially for each cell as described previously [20]. All images were analyzed in a blinded fashion. Briefly, a FIJI macro was used to define the center of the nucleus and remove the signal of neighboring cells. From the manually defined center point, the GRP75 signal intensity was mapped to polar co-ordinates with re-scaling to correct for artifacts generated by the square pixel shape. The location of the edge of the cell and edge of the nuclear envelope were defined in polar co-ordinates. The fluorescence signal was then re-scaled to a normalized axis where the center of the cell to the cell periphery corresponded to 0 to $100 \%$. In addition, the nucleoplasm was scaled as 0 to $25 \%$, as a control for nuclear size. The mean distribution radius was calculated using Matlab scripts as previously described [20]. The morphology of the mitochondrial network as reticular, rounded, or both reticular and rounded (i.e. mixed morphology) was manually scored in a blinded fashion.

\subsection{Transmission Electron Microscopy}

The preparation of cells for transmission electron microscopy was performed as described previously [45]. Briefly, NCI-H460 and A549 cells were plated onto tissue culturetreated plastic. Seventy-two hours later, cells were rinsed quickly in warm Sorensen's Buffer and fixed in pre-warmed $\left(37^{\circ} \mathrm{C}\right) 2.5 \%$ glutaraldehyde $/ 2 \%$ paraformaldehyde solution (Proscitech, Kirwan, Australia) in Sorensen's Buffer for $1 \mathrm{~h}$ at room temperature. Cells were further processed as described previously [46]. $60 \mathrm{~nm}$ ultrathin sections were cut on an Ultracut 6 (Leica Microsystems, Singapore) ultramicrotome. Grids were imaged at $80 \mathrm{kV}$ on a JEOL 1011 transmission electron microscope fitted with a Morada $4 \mathrm{~K} \times 4 \mathrm{~K}$ Soft Imaging Camera at two-fold binning (Olympus, Hong Kong). Mitochondrial volume density as a percentage of cytoplasmic volume was determined by stereology using point counting with a double lattice grid on systematically captured random images. Percentage 
mitochondrial area was averaged for 8-23 cells per biological replicate for $n=3$ (A549) and $n=2$ (NCI-H460) biological replicates (separate cell cultures).

\subsection{Preparation of NCI-H460 cells for Lattice Light-Sheet Imaging of Mitochondria}

NCI-H460 cells (NCI-H460 Ctrl $\mathrm{SH}_{2}$ or NCI-H460 $\beta \mathrm{III}_{\mathrm{SH} 4}$ ) were seeded in 6-well plates at $2.5 \times 10^{5}$ cells per well and incubated $24 \mathrm{~h}$ to allow attachment. For characterizing overall mitochondrial numbers and volumes, cells were incubated with MitoTracker Green (M7514, Invitrogen) according to the manufacturer's instructions. For assaying fusion between mitochondria, cells were transfected with the photo-activatable mitochondrial marker, mito-Dendra2 (Addgene \#55796) at $1 \mu \mathrm{g}$ DNA per well using Lipofectamine 2000 (Thermo Fisher, Waltham, MA, USA) according to the manufacturer's instructions. Following $24 \mathrm{~h}$ incubation, cells were detached via trypsinization, counted, and seeded again into 6-well plates containing several $5 \mathrm{~mm}$ glass coverslips at $1 \times 10^{5}$ cells per well, and allowed a further $24 \mathrm{~h}$ to attach to the coverslips before commencing lattice light-sheet imaging.

\subsection{Lattice-Light Sheet Imaging Mitochondrial Dynamics}

Cells were imaged using a lattice light sheet microscope (3i, Denver, CO). Excitation for MitoTracker Green or Dendra-2 was achieved using $488 \mathrm{~nm}$ diode lasers (MPB communications) at $1-5 \%$ AOTF transmittance through an excitation objective (Special Optics $28.6 \times 0.7$ NA 3.74-mm immersion lens) and detected via a Nikon CFI Apo LWD $25 \times 1.1$ NA water immersion lens with a $2.5 \times$ tube lens. Live cells were imaged in $9 \mathrm{~mL}$ of $37^{\circ} \mathrm{C}$ heated DMEM and were acquired with $2 \times$ Hamamatsu Orca Flash 4.0 V2 sCMOS cameras with a dichroic at $560 \mathrm{~nm}$. Photoconversion of Dendra-2 was achieved by interleaving the excitation sequence with $488 \mathrm{~nm}$ Beam at high laser power in single Bessel beam mode.

\subsection{Analysis of Lattice-Light Sheet Imaging of Mitochondrial Dynamics}

Segmentation and tracking of mitochondria were performed using a combination of ORS Dragonfly and custom codes. Image threshold was performed at upper Otsu and eroded in 3D with a kernel size of 3. Speckle noise and backgrounds over thresholds were removed by removing voxel counts less than 10. Tracking was performed by custom MATLAB codes based on CME analysis [47]. Statistical analysis comparing control cells with those expressing $\beta$ III-tubulin-targeted shRNA was performed using two-way ANOVA or Mann-Whitney U test for multiple and single comparisons, respectively.

\subsection{Code Availability}

Information and requests for Matlab codes should be directed to the Lead Contact Maria Kavallaris.

\subsection{Statistical Analysis}

Data are presented as the mean \pm standard error of the mean (SEM) unless otherwise stated. Data were analyzed using a Kruskal-Wallis test (non-parametric ANOVA) with Dunn's multiple comparison test for more than two groups or Student's $t$-test for two group comparisons where appropriate (GraphPad Prism 5, Graphpad Software Inc., La Jolla, CA, USA). Analysis of mass spectrometry data was performed in the software described above, and in R (v3.6.3). A $p$-value less than 0.05 was considered statistically significant. The Bonferroni-Hochberg method was used to correct $p$-values for multiple comparisons.

Further information and requests for resources and reagents should be directed to, and will be fulfilled by, the Lead Contact, Maria Kavallaris.

\section{Results}

\subsection{BIII-Tubulin Regulates the Mitochondrial Network Structure and Morphology}

The role of $\beta$ III-tubulin in regulating the mitochondrial network was investigated in two independent non-small cell lung cancer (NSCLC) cell lines with endogenous expression of $\beta$ III-tubulin using stable specific knockdown of this isotype [4]. As indicated in previous 
studies, stable $\beta$ III-tubulin suppression of approximately $90 \%$ was achieved in these isogenic A549 and H460 non-small cell lung cancer cell lines [4], with no perturbation in the expression of other $\beta$-tubulin isotypes [23], microtubule cytoskeletal architecture [48], microtubule dynamics or proliferation rates in steady-state normal growth conditions $[5,23,44]$. However, the effect of $\beta$ III-tubulin on mitochondrial architecture had not yet been explored. To visualize the mitochondrial network, immunofluorescence staining for the mitochondrial marker mtHSP70/GRP75 [49,50] was performed. Comparison of control (H460 Ctrl $\mathrm{SH}_{2}$; A549 $\mathrm{Ctrl}_{\mathrm{SH} 27}$ ) cells and cells with suppressed levels of $\beta$ III-tubulin (H460 $\beta \mathrm{IIII}_{\mathrm{SH} 4} ; \mathrm{A} 549$ $\beta \mathrm{III}_{\mathrm{SH} 1}$ ) (Figure 1A, Supplementary Figure S1A) identified that mitochondria form a tubular, reticular network that extends to the cell periphery in NCI-H460 and A549 control cells, with the A549 cell line in general having a more centralized mitochondrial network compared with the NCI-H460 cell line (Figure 1A). Comparatively, the mitochondrial network appeared subtly but nonetheless discernibly more perinuclear in NSCLC cells with suppressed $\beta$ III-tubulin expression compared with control cells (Figure 1A).

To generate a quantitative, robust and unbiased characterization of the mitochondrial distribution throughout the cytoplasm, we applied a recently developed image analysis algorithm to immunofluorescence images of control and $\beta$ III-tubulin knock-down cells stained with the mitochondrial marker GRP75 to quantify the mitochondrial distribution radially across the entirety of each cell [20] (Figure 1B,Ci,Cii). The mean distribution radius parameter calculated from this analysis provides a measure of mitochondrial distribution towards the cell periphery, and a larger radius indicates that mitochondria are localized towards the cell periphery (Figure 1Biv). This analysis indicated that the mitochondrial network of cells with suppressed $\beta$ III-tubulin expression was more perinuclear than control cells (Figure 1D).

Analysis of the morphology of this mitochondrial network indicated that the network was also more fragmented and rounded in cells with suppressed levels of $\beta$ III-tubulin compared to the more reticular mitochondrial network structure in control cells (Figure 1E).

This phenotype, consisting of a more perinuclear and rounded mitochondrial network in BIII-tubulin knockdown cells, was exacerbated in glucose starvation conditions in $\mathrm{H} 460$ cells (Supplementary Figure S1A-C), with glucose starvation known to induce mitochondrial network reorganization to respond to the bioenergetic and endoplasmic reticulum stress induced by nutrient deprivation. Mitochondrial rounding, network fragmentation and a centralized mitochondrial distribution in $\beta$ III-tubulin knockdown cells is consistent with mitochondrial membrane potential depolarization and retrograde transport of mitochondria targeted for degradation [16,51-54]. However, quantitation of mitochondrial membrane potential using JC- 1 staining and FACS analysis showed that $\beta$ III-tubulin expression did not affect the mitochondrial membrane potential (Supplementary Figure S1E). Together, this indicates that $\beta$ III-tubulin expression enables a more extended reticular mitochondrial network in NSCLC cells.

\subsection{BIII-Tubulin Regulates Mitochondrial Volume}

To examine the effect of $\beta$ III-tubulin expression on mitochondrial ultrastructure and volume in more detail, we performed transmission electron microscopy (TEM) on cells with endogenous and suppressed expression of $\beta$ III-tubulin. Consistent with the light microscopy analysis (Figure 1), mitochondria appeared more perinuclear in A549 $\beta$ III-tubulin knockdown cells (Figure 2A and Supplementary Figure S1F). Similarly, there was a trend towards mitochondria being less tubular and more rounded in knockdown cells compared with control cells (Figure 2B, $p=0.12$ ). In addition, precise quantitation of mitochondrial volume showed that suppression of $\beta$ III-tubulin expression significantly reduced the mitochondrial volume in A549 (50.69 $\pm 12.29 \%$ mean $\pm \mathrm{SD}, p=0.003$ ) (Figure 2A,Ci) and NCI-H460 cells $(70.07 \pm 10.26 \%, p=0.0459)$ (Figure 2Cii) compared with control cells. 
A

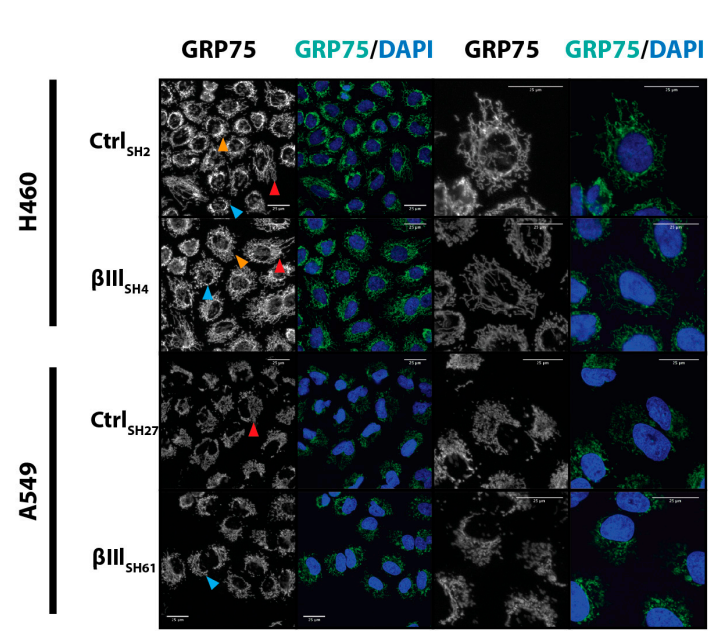

Ci

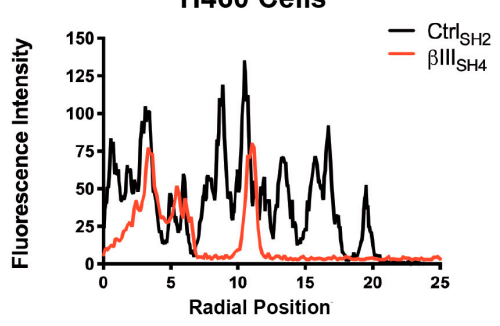

Bi
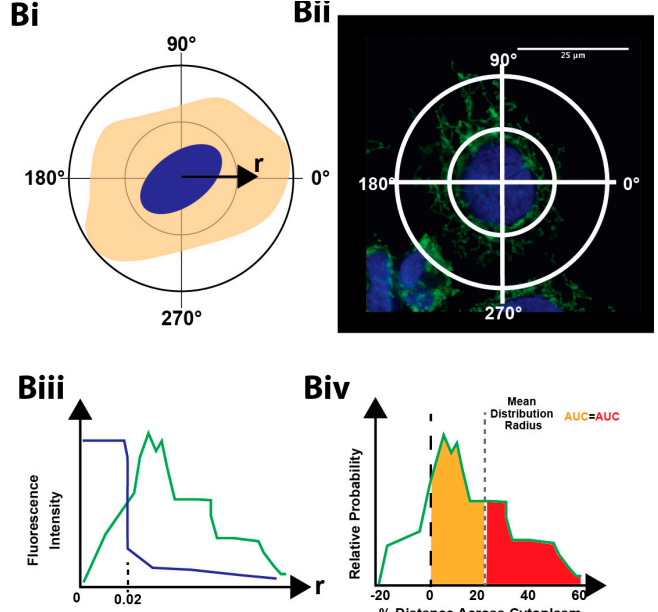

Biv

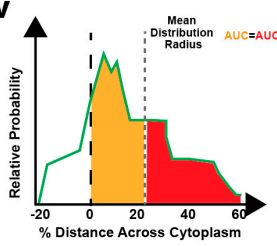

Cii

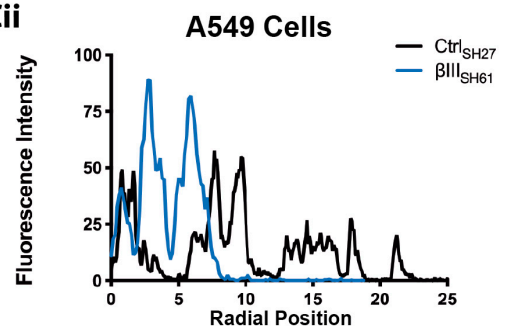

Di
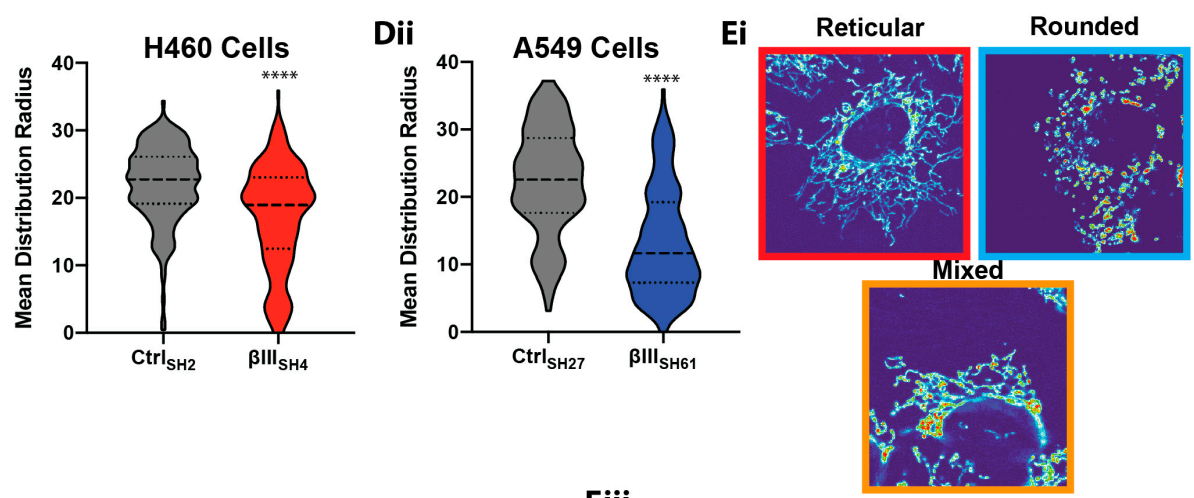

Eii

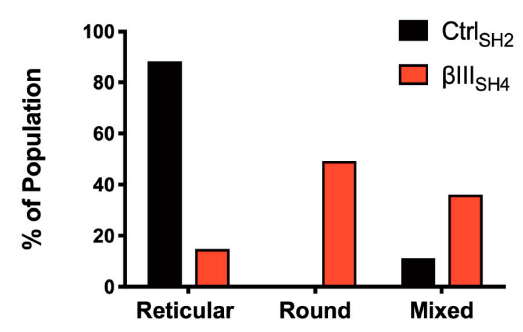

Eiii

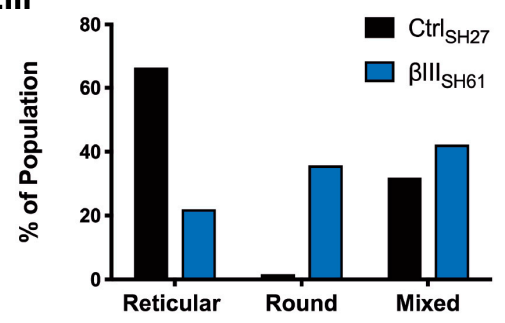

Figure 1. $\beta$ III-tubulin regulates mitochondrial network structure and morphology. (A) Mitochondrial network distribution by GRP75 immunofluorescence staining (left panel: greyscale; right panel: GRP75 green, DAPI blue) in NCI-H460 and A549 cells expressing control (NCI-H460 Ctrl SH2 $_{2}$ A549 $\left.\mathrm{Ctrl}_{\mathrm{SH} 27}\right)$ and $\beta \mathrm{III}-$ tubulin targeted shRNA (NCI-H460 $\beta \mathrm{III}_{\mathrm{SH} 4}, \mathrm{~A} 549$ $\left.\beta \mathrm{III}_{\mathrm{SH} 61}\right)$. Red arrowhead: reticular mitochondrial morphology; blue arrowhead: rounded morphology; orange arrowhead: mixed morphology. Scale bars 25um. Representative of $n=3$ independent experiments. Pseudocolored images show signal intensity from low (blue) to high (red) with high magnification images in Supplementary Figure S1A. (B) Workflow overview to measure the distribution of mitochondrial throughout the cytoplasm. Signal intensities for individual cells are transformed into polar co-ordinates defined 
as a radial distance from the centre of the nucleus at a specific angle (Bi,Bii). The edge of the nucleus and cytoplasm is defined (Biii) and the signal intensity is scaled to 0 to $100 \%$ corresponding to the centre of the nucleus $(0 \%)$ to the edge of the cytoplasm $(100 \%)$, with the edge of the nucleus at $25 \%$. The mean distribution radius is defined at the radial position, $r$, where the integrated relative probability of the signal is equal from between the nucleus and $r$ and between the edge of the cytoplasm and $\mathbf{r}$ (Biv). (C) Representative fluorescence intensity profile of GRP75 expression from the edge of the nucleus in NCI-H460 (Ci) and A549 (Cii) cells. (D) Mitochondrial mean distribution radius in NCI-H460 (Di) and A549 (Dii) cells. ${ }^{* * *} p<0.0001$. Data from the analysis of 30-60 cells from each condition for each of $n=3$ independent experiments. (Ei) Representative images of reticular, rounded and mixed mitochondrial morphologies. Signal intensity is pseudocolored as a thermal look up table to convey signal distribution. The proportion of cells with rounded, reticular or mixed mitochondrial morphology in NCI-H460 (Eii) and A549 (Eiii) cells. Data from 100 cells from three independent experiments.

\subsection{The BIII-Tubulin C-Terminal Tail Regulates the Mitochondrial Network Structure and Morphology}

The C-terminal tail of the $\beta$ III-tubulin protein distinguishes this tubulin isotype from other $\beta$-tubulin isotypes [3]. In order to examine the differential importance of the $\beta$ IIItubulin body and C-terminal tail structural domains on the mitochondrial network, geneedited NCI-H460 cell lines were engineered to express the full-length $\beta I I I-t u b u l i n$ protein (ZB3) compared with cell lines gene-edited to express a truncated version of the protein lacking the C-terminal tail region from Ala429 (ZB3 $\Delta$ ), or with the $\beta I$-tubulin C-terminal tail sequence in substitution for the $\beta$ III-tubulin sequence (ZB3/CB1) or with the $\beta$ III-tubulin body replaced with the $\beta$ I-tubulin body (ZB1/CB3) [3]. These genetically modified cell lines were grouped into two panels with matched expression levels, with each panel expressing the modified proteins at $30 \%$ and $100 \%$ of the endogenous $\beta$ III-tubulin expression, as described previously [3]. Replacement of the endogenous $\beta$ III-tubulin gene expression using gene-editing did not affect cell proliferation, microtubule cytoskeletal architecture or dynamics relative to the parental NCI-H460 cell line, confirming that the gene-editing approach itself does not artefactually affect microtubule behavior or cell proliferation [3]. Modification of the $\beta$ III-tubulin structural domains also did not affect the $\beta$-tubulin isotype composition or actin cytoskeletal architecture in normal growth conditions (data not shown).

To examine if the structural domains of $\beta$ III-tubulin affect the distribution of mitochondria in the cell, we applied the quantitative, whole-cell analysis method described above to immunofluorescence images of these gene-edited cells stained with the mitochondrial marker GRP75. It identified that, similarly to our findings in cells with suppressed expression of the full-length $\beta$ III-tubulin protein (Figures 1 and 2), loss of the $\beta$ III-tubulin $C$-terminal tail either through truncation of the protein $(Z B 3 \Delta)$ or replacement with the $\beta I$-tubulin C-terminal tail (ZB3/CB1) resulted in subtle but significant localization of the mitochondrial network to the perinuclear region compared with the full-length protein (ZB3; Figure 3A-C). Conversely, replacement of the $\beta$ III-tubulin body with the $\beta$ I-tubulin sequence (ZB1/CB3) partially extended the mitochondrial network towards the cell periphery in one expression-matched set of clones (Figure 3Bi), further supporting a role for the $\beta$ III-tubulin tail itself in promoting an extended mitochondrial network.

Morphologically, loss of the $\beta$ III-tubulin C-terminal tail, either by truncation of the tail $(\mathrm{ZB} 3 \Delta)$ or replacement of the $C$-terminal tail with the $\beta I$-tubulin sequence $(Z B 3 / C B 1)$, promoted a more fragmented and rounded mitochondrial network morphology (Figure 3C) consistent with our findings in cells with suppressed expression of $\beta$ III-tubulin. Replacement of the $\beta$ III-tubulin body with the $\beta I$-tubulin body also produced a more rounded and fragmented mitochondrial network compared with cells expressing the full-length $\beta$ III-tubulin protein (Figure 3C), but its effect was not as pronounced as that induced by the $\mathrm{C}$-terminal tail sequence. This indicates that while the $\beta$ III-tubulin body and C-terminal tail both contribute to a more extended reticular mitochondrial network, the sequence of the $\beta$ III-tubulin C-terminal tail, not just its presence or absence, more significantly reg- 
ulates mitochondrial network localization and architecture than the tubulin body in an isotype-specific manner.

A

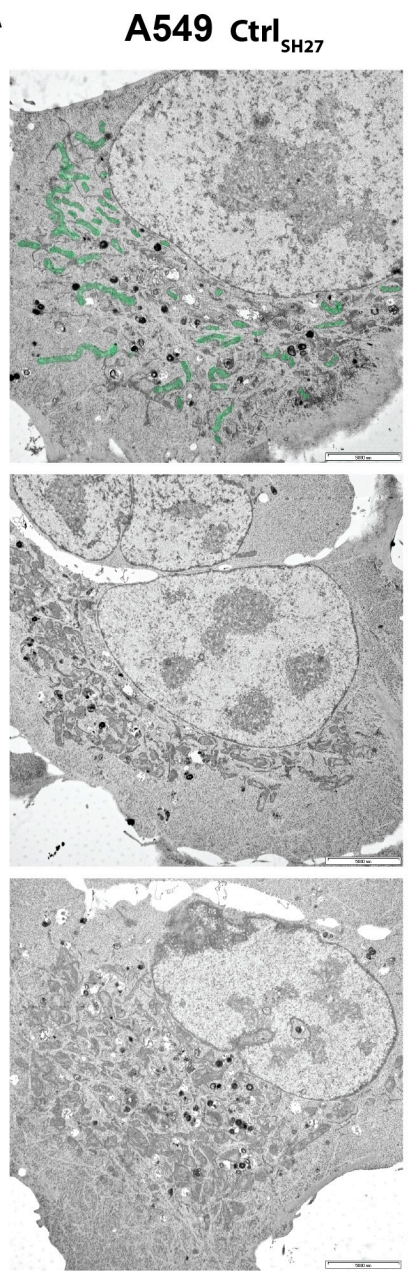

$\mathrm{H} 460 \mathrm{Ctrl}_{\mathrm{SH} 2}$

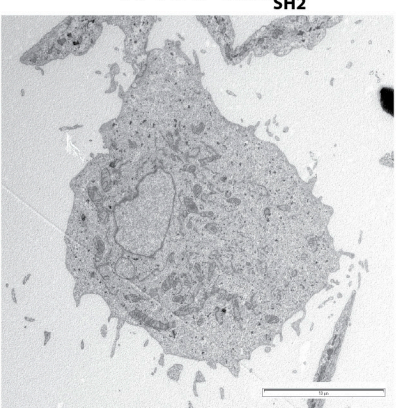

A549 BIII $_{\text {SH61 }}$
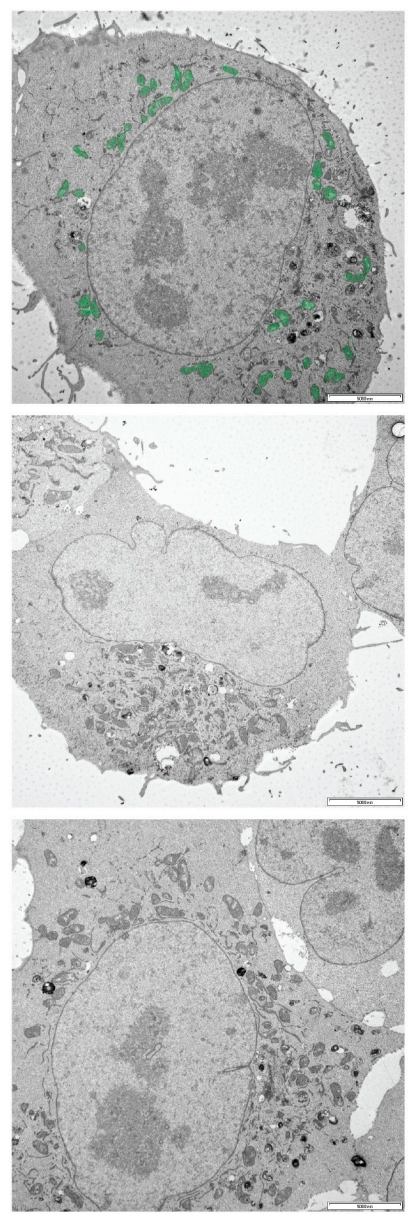

H460 $\beta$ IIII $_{\text {SH4 }}$

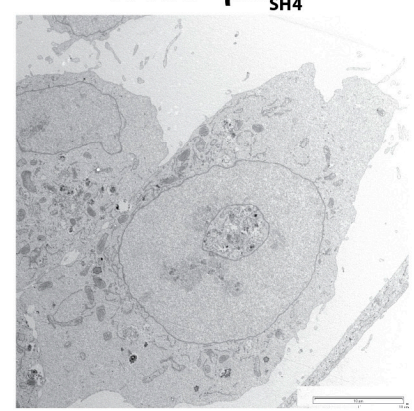

B

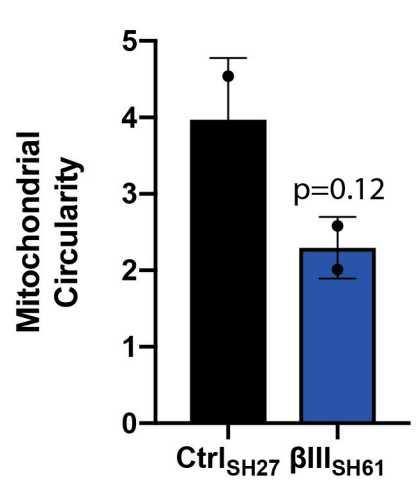

Ci
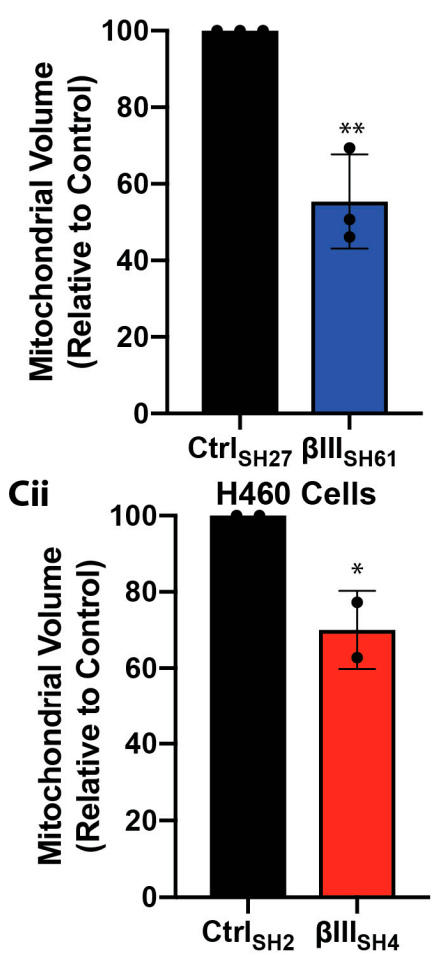

Figure 2. $\beta$ III-tubulin regulates mitochondrial volume. (A) Representative electron micrographs of NCI-H460 and A549 cells expressing control (H460 Ctrl $\left.\mathrm{SH}_{2}, \mathrm{~A} 549 \mathrm{Ctrl}_{\mathrm{SH} 27}\right)$ and $\beta \mathrm{III}-$ tubulin targeted shRNA (NCI-H460 $\beta \mathrm{III}_{\mathrm{SH} 4}, \mathrm{~A} 549 \beta \mathrm{III}_{\mathrm{SH} 61}$ ). Mitochondria in the upper panels have been pseudocolored green to allow simple comparison of the two cell types (see Supplementary Figure S1C for uncolored original images). Scale bar $5 \mu \mathrm{m}$. (B) Mitochondrial circularity in A549 cells expressing control (A549 $\mathrm{Ctrl}_{\mathrm{SH} 27}$ ) and $\beta \mathrm{III}-$ tubulin targeted shRNA (A549 $\beta \mathrm{III}_{\mathrm{SH} 61}$ ) (mean $\pm \mathrm{SD}$ of $n=2$ independent experiments, $p=0.12$ ). Points are the average of each independent experiment. (C) Mitochondrial volume in control and $\beta$ III-tubulin knockdown cells in A549 cells $(\mathbf{C i}$, mean \pm SD of $n=3$ independent experiments, $p=0.0033$ ) and NCI-H460 cells (Cii, mean \pm SD of $n=2$ independent experiments, $p=0.0459)$. Points are the average of each independent experiment. ${ }^{*} p<0.05,{ }^{* *} p<0.01$. 

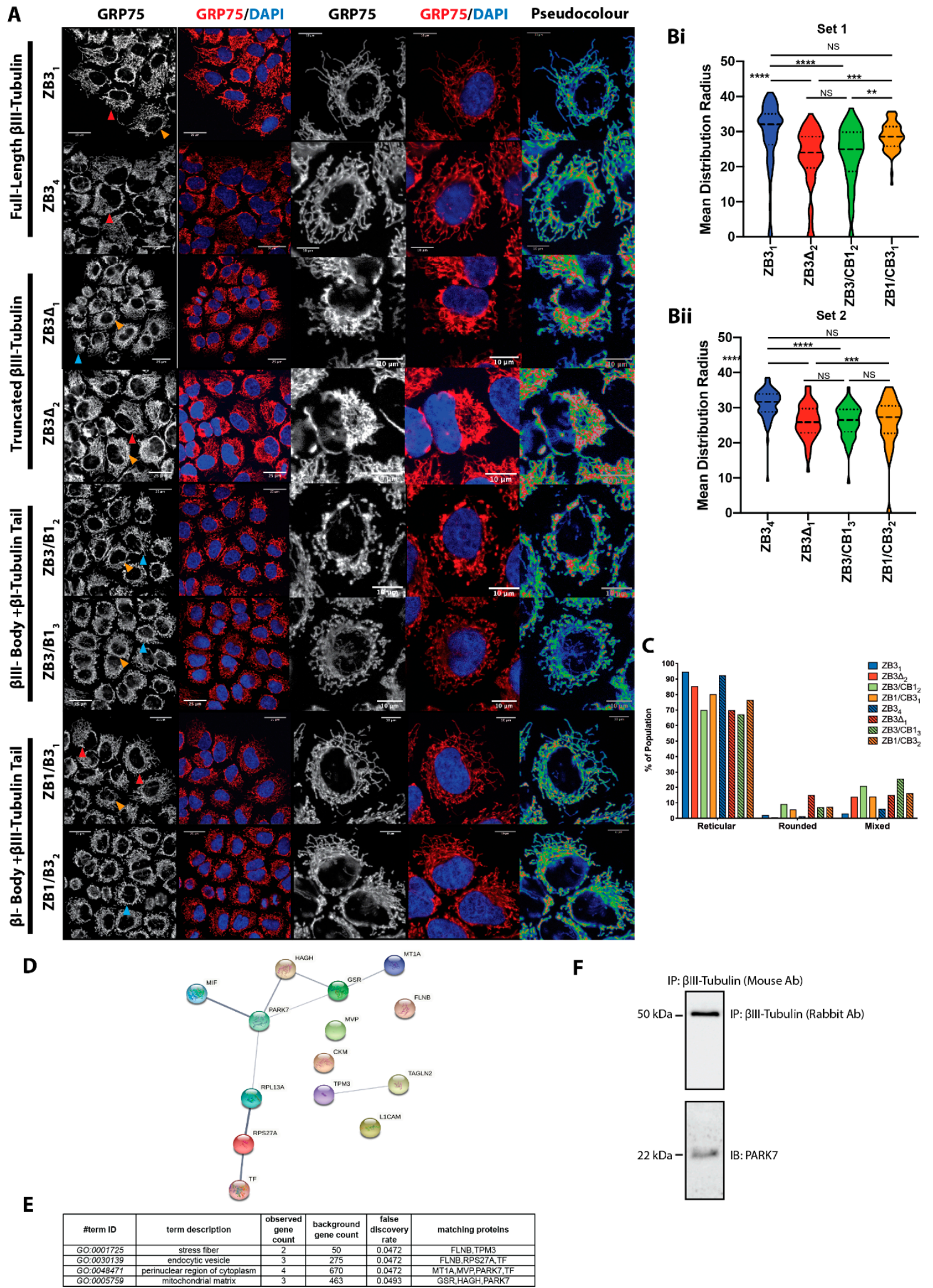

Figure 3. The $\beta$ III-tubulin C-terminal tail regulates mitochondrial network structure and morphology. (A) Mitochondrial network distribution by GRP75 immunostaining (left panel: greyscale; right panel: GRP75 green, DAPI blue) in NCI-H460 expressing the full-length $\beta$ III-tubulin protein (ZB3), truncated $\beta$ III-tubulin (ZB3 $\Delta)$, $\beta$ III-tubulin with $\beta$ I-tubulin C-terminal tail (ZB3/CB1), and $\beta I$-tubulin 
with $\beta$ III-tubulin C-terminal tail (ZB1/CB3). Scale bars $25 \mathrm{~mm}$ for lower magnification and $10 \mathrm{~mm}$ for higher magnification. Red arrowhead: reticular mitochondrial morphology; blue arrowhead: rounded morphology; orange arrowhead: mixed morphology. Scale bars $25 \mathrm{~mm}$. Pseudocolored images show signal intensity from low (blue) to high (red). Representative of $n=3$ independent experiments. (B) Mitochondrial mean distribution radius for Set 1 (Bi) and Set 2 (Bii) gene-edited cells. Non-parametric ANOVA with Dunn's correction for multiple comparisons. NS: non-significant, ${ }^{* *} p<0.01,{ }^{* * *} p<0.001,{ }^{* * * *} p<0.0001$. Data from the analysis of more than 45 cells from $n=3$ independent experiments. (C) The proportion of cells with rounded, reticular or mixed mitochondrial morphology. Data from at least 120 cells per clone from three independent experiments. (D) Interaction network of proteins that exclusively interact with $\beta$ III-tubulin. (E) Functional annotation analysis identifies enrichment of $\beta$ III-tubulin-associated proteins in cellular compartments (GO terms). (F) Validation of the interaction between $\beta$ III-tubulin and PARK7 by western blotting (representative of $n=3$ independent experiments).

The C-terminal tail of $\beta$-tubulin proteins is a site for protein-protein interactions that are thought to confer as yet poorly defined isotype-specific functionality [6]. To explore protein-protein interactions that occur specifically with the $\beta$ III-tubulin isotype, we performed $\beta$-tubulin immunoprecipitation and proteomic mass spectrometry analysis (Figure 3F). As expected, this analysis identified $\alpha_{-}, \beta-$ and $\gamma$-tubulin isotypes expressed in this cell line and known to be associated with $\beta$ III-tubulin and $\beta I$-tubulin (TBA, TBA1C, TBA3C, TBA3E, TBA8, TBB3, TBB5, TBB, TBB1, TBB6, TBB4B, TBB2, TBG1, TBG2) as well as microtubule associated proteins (MAP4, MAP1A) as pulled down with both $\beta$ I-tubulin and $\beta$ III-tubulin proteins. This confirmed enrichment of the target $\beta$-tubulin isotype of interest while retaining interactions between these tubulin isotypes and microtubuleinteracting proteins.

Importantly, we identified 14 proteins that specifically interact with $\beta$ III-tubulin but not with $\beta I$-tubulin (Supplementary Figure S2A, Supplementary Table S1). Functional annotation analysis identified that these $\beta$ III-tubulin-associated proteins were significantly enriched in the mitochondrial matrix and the perinuclear region of the cytoplasm (Supplementary Figure S2D), consistent with a role for $\beta$ III-tubulin in regulating mitochondrial network architecture and trafficking of mitochondria away from perinuclear locations. While the majority of these proteins are known to be localized to the outer mitochondrial membrane and cytoplasm and therefore have the potential to interact directly with $\beta I I I-t u b u l i n, H A G H$ is localized to the mitochondrial matrix, so its interactions may be facilitated by other, as yet unidentified, scaffolding proteins (Supplementary Table S1). Interestingly, this analysis identified a regulator of mitochondrial dynamics, PARK7/DJ-1, as associated with $\beta$ III-tubulin but not $\beta$ I-tubulin (Figure 3F,H, Supplementary Figure S2S). The cytoplasmic localization of this protein $[55,56]$, means it has the potential to interact with $\beta$ III-tubulin. Protein interaction network analysis identified this protein as central to a broader network of proteins that also specifically interact with $\beta$ III-tubulin (Figure $3 \mathrm{~F}$ ), suggesting that protein-protein interactions specific to $\beta$ III-tubulin have the potential to directly affect mitochondrial network architecture. Further validation of this finding may confirm if a specific interaction of this mitochondrial regulator with this tubulin isotype contributes to the regulation of mitochondrial architecture by $\beta$ III-tubulin. Other proteins in this interaction network may also indirectly modulate mitochondrial volume and architecture through $\beta$ III-tubulin. The actin cytoskeletal regulator tropomyosin $3 \mathrm{~A}$ was also pulled down with $\beta$ III-tubulin (Figure 3F). The actin cytoskeleton is known to regulate mitochondrial dynamics and, therefore, altered actin dynamics may indirectly mediate the effects of $\beta$ III-tubulin. These findings warrant further investigation into the direct and indirect molecular mechanisms that may contribute to $\beta$ III-tubulin-mediated mitochondrial regulation. 


\subsection{BIII-Tubulin Promotes a Dynamic Mitochondrial Network}

Mitochondria localization and network architecture result from changes in the fission, fusion and trafficking of mitochondria throughout the cytoplasm, enabling adaptive responses to stimuli and cellular stress. To determine if these effects of $\beta I I I-t u b u l i n$ on the mitochondrial network architecture and volume may reflect its effects on mitochondrial network dynamics, we used dynamic lattice light sheet microscopy (LLSM) to quantitatively compare mitochondrial dynamics in real time in cells with suppressed $\beta$ III-tubulin expression compared with control cells. LLSM allows for fast, volumetric imaging necessary to capture the total number of mitochondria and their dynamic behavior throughout the entire volume of each cell (Figure 4A-C). By segmenting the intensity of MitoTracker Green (Figure 4B), we quantified the volume of individual mitochondria as well as the total number of mitochondria in the whole volume of the cell for control and $\beta I I I-t u b u l i n$ knockdown cells (Figure 4C). Consistent with our previous observations in static immunofluorescence analysis (Figure 1), this dynamic imaging modality also revealed a fragmented mitochondrial network in cells with suppressed $\beta$ III-tubulin expression (Figure 4C, Supplementary movies). The mean volume of mitochondria in $\beta$ III-tubulin knockdown cells was also significantly reduced $\left(1.9 \pm 1.3 \mu \mathrm{m}^{3}\right)$ compared with control cells $\left(3.8 \pm 3.1 \mu \mathrm{m}^{3}, p<0.01\right.$, Figure $4 \mathrm{D}$ ), as measured by TEM (Figure 2). Similarly, the number of mitochondria in control cells was approximately half of that in $\beta$ III-tubulin knockdown cells at any single time point (Figure $4 \mathrm{E}$ ), together reflecting a more fragmented mitochondrial network in $\beta$ III-tubulin knockdown cells (Figure 4C).

Perturbations in mitochondrial velocity, fission and fusion dynamics can result in the strong effects on the size and number of mitochondria that we observed in $\beta$ III-tubulin knockdown cells. Therefore, we further investigated if $\beta$ III-tubulin expression affected mitochondrial motility and dynamics. We utilized the photoconvertible protein Mito-Dendra2 to precisely track the motility and fusion dynamics of individual mitochondria within the cytoplasm of control and $\beta$ III-tubulin knockdown cells (Figure 4F). The use of MitoDendra2 provides superior quantitation of mitochondrial dynamics compared with the use of MitoTracker Green (Figure 4A,B) by focusing on photoconverted mitochondria within a volume containing dense, dynamic non-photoconverted mitochondria (Figure $4 \mathrm{~F}-\mathrm{H}$ ). There was a consistent trend towards reduced maximal mitochondrial velocities in $\beta$ III-tubulin knockdown cells $(0.37 \mu \mathrm{m} / \mathrm{s})$ compared with control cells $(0.51 \mu \mathrm{m} / \mathrm{s})(p=0.0612$, Figure $4 \mathrm{I})$. By segmenting out the signal of photoconverted Dendra2 channel and measuring the total intensity of individual mitochondria in this channel as well as the non-photoconverted channel, we counted the number of double-colored mitochondria (Figure 4G,H). Since $\beta I I I-$ tubulin knockdown cells have double the number of mitochondria compared with control cells (Figure 4E), it would be expected that if the rate of mitochondrial fission and fusion are equivalent in the two cell lines, then the growth in the number of double-colored mitochondria in $\beta I I I-$ tubulin knockdown cells should be approximately double that of control cells. However, we observed that the growth of double-labelled mitochondria occurred at only a marginally higher rate in $\beta$ III-tubulin knockdown cells compared with control cells (Figure 4J). Therefore, we reasoned that mitochondrial fusion still occurs when $\beta I I I-t u b u l i n$ expression is suppressed and the potential effect of $\beta$ III-tubulin expression in increasing mitochondrial fusion dynamics requires a more sensitive approach to discern more subtle effects.

Overall, the quantitative imaging modalities employed in this work reveal an isotypespecific role for the $\beta$ III-tubulin protein, mediated principally by its $C$-terminal tail region, in regulating mitochondrial number, size and speed. Protein-protein interaction analysis indicates that this tubulin isotype specifically interacts with regulators of mitochondrial dynamics. Together this provides new insight into an isotype-specific role for $\beta I I I-t u b u l i n$ in regulating the dynamics of the mitochondrial network by advancing our understanding of the tubulin code. 
A

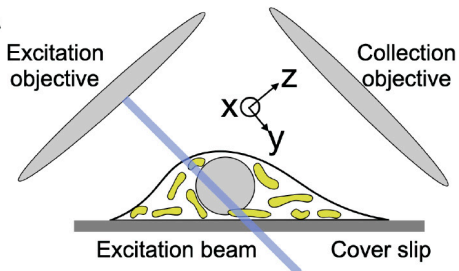

B

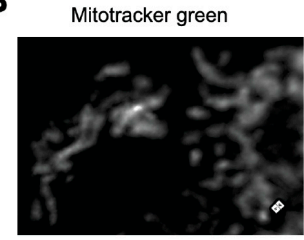

C

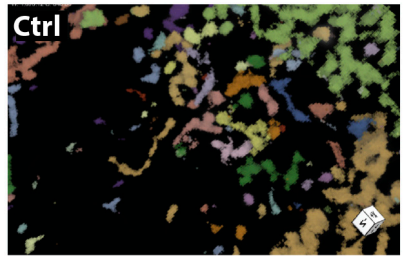

$\mathbf{F}$

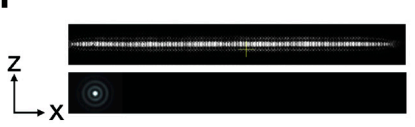

imaging lattice beam

Local photoconversion by single
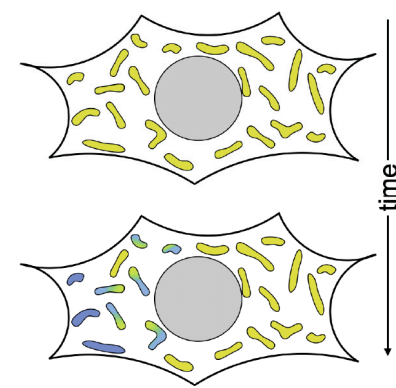
Bessel beam

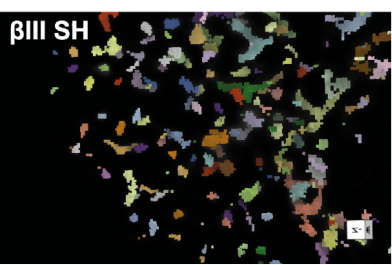

G

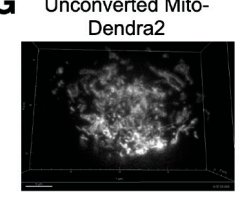

Converted Mito-Dendra2
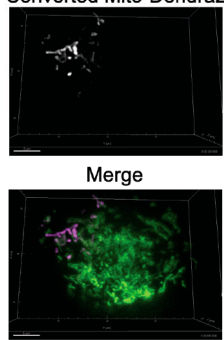

Segmentation

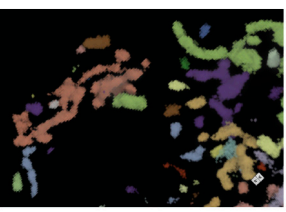

D $n=10$ cells
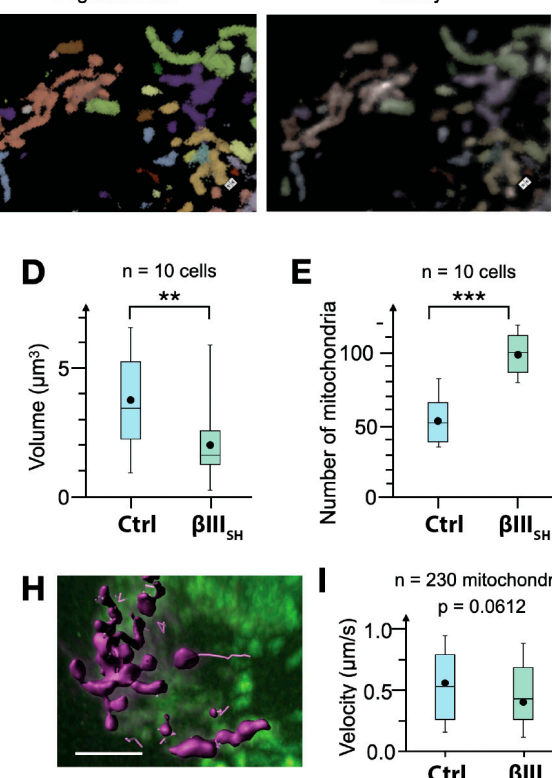

E
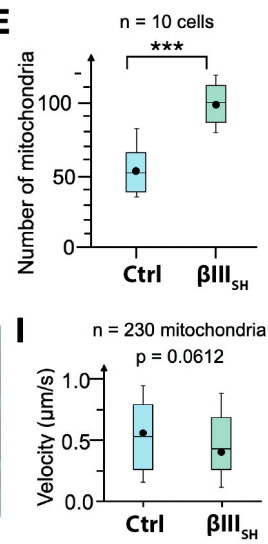

J

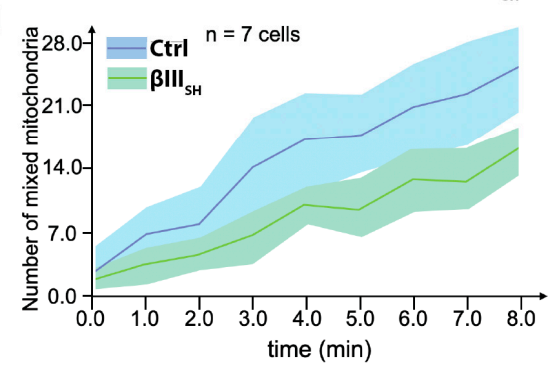

Figure 4. $\beta$ III-tubulin regulates mitochondrial dynamics. (A) Schematic of mitochondria imaging using the lattice light-sheet microscope. The blue line represents the plane of excitation. (B) Representative image of MitoTracker Green intensity, segmentation and overlay. (C) Mitochondria in control cells have larger volume and show high-aspect ratio in comparison to cells expressing $\beta I I I-t u b u l i n$ targeted shRNA $\left(\beta \mathrm{III}_{\mathrm{SH}}\right)$. (D) Mitochondrial volumes as measured from segmentation of 3D images. ${ }^{* *} p<0.01$. (E) Total number of mitochondria in whole cells, ${ }^{* * *} p<0.001$. (F) Schematic of single Bessel beam-based photo-conversion of Mito-Dendra2 to track individual mitochondria particles and fusions. Axes shown correspond to the geometry depicted in (A). (G) A representative image of a cell showing mito-Dendra2 post-photoconversion. (H) Segmentation and tracking of mitochondria in the converted channel enable quantitation of mitochondrial fusion. (I) Mitochondrial speed in control cells and in cells expressing $\beta$ III-tubulin targeted shRNA $\left(\beta \mathrm{III}_{\mathrm{SH}}\right), p=0.0612(\mathrm{~J})$ Quantitation of double-colored mitochondria as a readout of mitochondrial fusion and mixing, $n=3$ independent experiments. $\mathrm{Ctrl}=$ Control cells; $\beta \mathrm{III}_{\mathrm{SH}}=$ cells expressing $\beta \mathrm{III}-$ tubulin targeted shRNA.

\section{Discussion}

The microtubule network integrates and regulates diverse intracellular functions at all stages of the cell cycle, yet the role of individual $\beta$-tubulin isotypes in health and disease remains unclear. In particular, the role of $\beta$-tubulin isotypes and their structural domains on mitochondrial architecture and dynamics in unknown. This study has identified a specific role for $\beta$ III-tubulin and its C-terminal tail in regulating mitochondrial dynamics, and promoting an extended, interconnected, and dynamic reticular mitochondrial network architecture. This is the first demonstration, to our knowledge, that the $\beta I I I-$ tubulin protein, and in particular its C-terminal tail, affects mitochondrial volume and architecture within the complex intracellular environment. 
Comparative analysis of $\beta$ III-tubulin with $\beta$ I-tubulin highlights that the sequence of the C-terminal tail of $\beta$ III-tubulin plays a more profound regulatory role than the tubulin body in regulating mitochondrial dynamics, and is consistent with this region of the protein being highly divergent compared with other $\beta$-tubulin isotypes. These findings are consistent with studies in reduced systems that have identified that the $\beta$ III-tubulin C-terminal tail reduces kinesin-1 processivity in an isotype specific manner [30], with kinesin proteins acting as important mediators of mitochondrial trafficking [31,32]. Our observations that both the $\beta$ III-tubulin body and C-terminal tail regulate mitochondrial dynamics may reflect the importance of both these $\beta$-tubulin regions as interacting sites for kinesin motors $[18,19]$. However, the more pronounced effect of the C-terminal tail on mitochondrial dynamics compared with the $\beta$ III-tubulin body is supported by observations that mutation of the $\beta$ III-tubulin helix 12 adjacent to the C-terminal tail region decreases mitochondrial trafficking to the axonal growth cone due to altered kinesin interactions in neurons [43]. Whether $\beta I I I-t u b u l i n$ promotes a more extended and interconnected mitochondrial architecture through kinesin-dependent or -independent mechanisms remains an active area of research in the laboratory. We have previously demonstrated that the $\beta$ III-tubulin C-terminal tail regulates microtubule dynamics [3] and this indirect, kinesin-independent mechanism may contribute to the effects of this tubulin isotype on mitochondrial dynamics. In addition, the tethering of mitochondria to microtubules by as yet undefined mechanisms regulates both mitochondrial fission [25] and microtubule dynamics [24,26]. Loss of $\beta$ III-tubulin expression or its C-terminal tail may therefore provoke the dissociation of mitochondria from the microtubule cytoskeleton, thereby inducing slow mitochondrial dynamics together with increased mitochondrial fusion and clearance. Whether $\beta$ III-tubulin regulates mitochondrial dynamics by acting as a scaffold for mitochondrial-microtubule interactions or through its effects on microtubule dynamics remains to be clarified. In addition, recent studies have revealed that post-translational modifications on specific microtubule subsets regulates the localization of the endoplasmic reticulum, with flow-on effects on autophagic vesicle and lysosomal localization [20]. Further studies investigating if the effect of $\beta$ III-tubulin expression is specific to mitochondria, can be generalized more broadly to other organelles, or results from changes in endoplasmic reticulum localization, are warranted.

Mitochondrial rounding and swelling, fragmentation of the mitochondrial network, and a more centralized mitochondrial distribution observed in cells with suppressed $\beta$ IIItubulin expression is consistent with depolarization of the mitochondrial membrane potential and retrograde transport of mitochondria targeted for degradation [16,51-54]. While we did not identify any significant effect of $\beta$ III-tubulin expression on basal mitochondrial membrane potential or mitochondrial ultrastructure, it remains possible that the mitochondrial network architecture associated with suppressed $\beta$ III-tubulin expression may reflect dysregulated mitochondrial quality control and turnover. Altered mitochondrial quality control and decreased mitochondrial function may explain the loss of metabolic flexibility and increased reliance on glycolytic metabolism to support bioenergetic and anabolic demand when $\beta$ III-tubulin expression is suppressed [4].

A role for $\beta$ III-tubulin in modulating mitochondrial dynamics has profound implications on health and disease. High expression of $\beta$ III-tubulin is correlated with poor patient outcome, disease progression and chemotherapy resistance in a number of cancers, including non-small cell lung cancer (NSCLC) $[4,44,48,57]$. Mitochondrial dynamics are also critical in NSCLC tumor maintenance, and mitochondrial localization and trafficking can have a significant influence on cell function, including hypoxic signaling [58]. Since mitochondrial clearance promotes tumor progression in NSCLC [59,60], $\beta$ III-tubulin's role in maintaining a functional active mitochondrial network may explain its association with aggressive advanced disease. Furthermore, recent studies highlighting the importance of localized metabolic control in driving focal adhesion turnover and cancer cell migration and invasion [61] suggest that the importance of $\beta$ III-tubulin in regulating these processes may support the metastasis of cancer cells that aberrantly express this protein. Certainly in neuronal cells, an extended mitochondrial network supports the metabolic requirements 
of long-range vesicular and organelle trafficking necessary to maintain cellular function across the entire neuronal cytoplasm [62].

While it is not yet clear if $\beta$ III-tubulin acts directly or indirectly on mitochondria, our analysis of protein-protein interactions has identified putative protein candidates that have the potential to directly mediate effects on mitochondrial architecture. PARK7 was identified as specifically interacting with $\beta I I I-t u b u l i n$ and is known to play a role in mitochondrial quality control, mitochondrial trafficking, and in maintaining mitochondrial-ER network homeostasis $[55,63]$. PARK7 is localized mainly to the cytoplasm. In response to oxidative stress, it relocalizes to the cytoplasmic side of the mitochondria [56]. While further validation of this interaction to define its context dependency is required, whether oxidative stress regulates the association of this protein with $\beta I I I-t u b u l i n$ is not yet clear. The role of PARK7/DJ-1 in regulating microtubule dynamics and ER stress in neurons [64], roles also played by $\beta$ III-tubulin $[2,4]$, further supports their potential role in functionally coupling mitochondrial dynamics to $\beta$ III-tubulin in the microtubule cytoskeleton. Interestingly, suppression of PARK7 expression in a neuroblastoma-based neuronal model also suppressed $\beta$ III-tubulin expression and microtubule dynamics, supporting the functional coupling of $\beta$ III-tubulin and PARK7 [64]. PARK7 interacts with VDAC [55], which has been strongly implicated in tubulin-mitochondrial interactions and the regulation of mitochondrial metabolism with $\beta$-tubulin isotype specificity in cell-free systems $[7,33,65]$. The disruption of ER-mitochondrial contacts by disruption of PARK7-VDAC interactions at the mitochondrial membrane is thought to affect autophagosome formation and mitochondrial fission and fusion [55], supporting a role for $\beta$ III-tubulin in autophagosome, ER and mitochondrial dynamics demonstrated in previous studies [4], and implicated by the findings of this study. These mechanisms are also thought to play an important role in the progression of Parkinson's Disease [55], suggesting that by regulating mitochondrial architecture, $\beta I I I-t u b u l i n$ may impact diverse cellular functions with implications in neuronal biology as well as cancer and Parkinson's Disease. These findings warrant further investigation to define the precise mechanisms by which $\beta$ III-tubulin regulates mitochondrial and ER homeostasis to impact stress response signaling.

Other minor $\beta$-tubulin isotypes ( $\beta$ II-tubulin and $\beta \operatorname{IV} \alpha$-tubulin) have also been associated with regulating mitochondrial localization specifically in cardiomyocytes [66-69], although the mechanisms by which they operate remain unknown. With increasing recognition for the combinatorial manner in which $\beta$-tubulin isotypes collectively regulate microtubule functions and microtubule-dependent processes in cells $[18,21,70]$, it is likely that the tubulin code regulating mitochondrial dynamics is a complex spatiotemporal network that depends on the local $\beta$-tubulin composition.

This study provides the first evidence that modulating the expression of $\beta$ III-tubulin or its structural domains alters mitochondrial localization and architecture in an isotypespecific manner. This insight into the tubulin code warrants further investigation to define the precise direct or indirect molecular mechanisms mediated by this specific $\beta$-tubulin isotype, with potentially far-reaching implications for many facets of biology in health and disease.

Supplementary Materials: The following supporting information can be downloaded at: https:/ www. mdpi.com/article/10.3390/cells11050776/s1, Figure S1: $\beta$ III-Tubulin regulates mitochondrial network structure and morphology in glucose-starved cells; Figure S2: $\beta$ III-Tubulin interacts with mitochondrial regulators; Table S1. Proteins identified as interacting with $\beta$ III-tubulin but not $\beta I$-Tubulin.

Author Contributions: Conceptualization, A.L.P., J.A.M. and M.K.; methodology, A.L.P., W.S.T., S.B., S.A., R.G.P.; software, S.A.; formal analysis, A.L.P., W.S.T., S.B., S.A., C.F., R.G.P.; investigation, A.L.P., W.S.T., S.B., U.K.M., S.A., C.F., R.G.P.; data curation, A.L.P., W.S.T., S.B., S.A., R.G.P.; writing—original draft preparation, A.L.P., J.A.M. and M.K.; writing—review and editing, A.L.P., W.S.T., S.B., U.K.M., S.A., C.F., R.G.P., J.A.M. and M.K.; visualization, A.L.P., S.A., R.G.P.; supervision, A.L.P., J.A.M., M.K.; project administration, M.K.; funding acquisition, S.A., R.G.P. and M.K. All authors have read and agreed to the published version of the manuscript. 
Funding: This work was funded by grants from the Australian Research Council (ARC Discovery Grant DP140103290 to MK), NHMRC (NHMRC Principal Research Fellowship APP1119152 to MK and APP1156489 to R.G.P; grants APP1140064 and APP1150083 to RGP), Cancer Australia Grant (PdCCRS 1141485 to MK and JAM), Cancer Institute NSW (CINSW Career Development Fellowship to JAM), UNSW (UNSW Research Excellence Award to ALP), Children's Cancer Institute (Children's Cancer Institute PhD Excellence Award to ALP) and Steggles PhD Scholarship (to ALP).

Institutional Review Board Statement: Not applicable.

Informed Consent Statement: Not applicable.

Data Availability Statement: Information and requests for Matlab codes should be directed to the Lead Contact Maria Kavallaris.

Acknowledgments: This work was supported by the Children's Cancer Institute, which is affiliated with the University of New South Wales (UNSW Sydney) and the Sydney Children's Hospital Network. The authors acknowledge the mass spectrometry expertise of Ling Zhong at the Bioanalytical Mass Spectrometry Facility, University of New South Wales, Australia. This research used facilities at the Biomedical Imaging Facility, Mark Wainwright Analytical Centre at UNSW, and the Microscopy Australia Research Facility at the Centre for Microscopy and Microanalysis at The University of Queensland.

Conflicts of Interest: The authors declare no conflict of interest.

\section{References}

1. Lopata, M.A.; Cleveland, D. In vivo microtubules are copolymers of available beta-tubulin isotypes: Localization of each of six vertebrate beta-tubulin isotypes using polyclonal antibodies elicited by synthetic peptide antigens. J. Cell Biol. 1987, 105, 1707-1720. [CrossRef]

2. Parker, A.L.; Ekavallaris, M.; McCarroll, J.A. Microtubules and Their Role in Cellular Stress in Cancer. Front. Oncol. 2014, 4, 153. [CrossRef] [PubMed]

3. Parker, A.L.; Teo, W.S.; Pandzic, E.; Vicente, J.J.; McCarroll, J.A.; Wordeman, L.; Kavallaris, M. $\beta$-Tubulin carboxy-terminal tails exhibit isotype-specific effects on microtubule dynamics in human gene-edited cells. Life Sci. Alliance 2018, 1, e201800059. [CrossRef] [PubMed]

4. Parker, A.L.; Turner, N.; McCarroll, J.; Kavallaris, M. $\beta$ III-Tubulin alters glucose metabolism and stress response signaling to promote cell survival and proliferation in glucose-starved non-small cell lung cancer cells. Carcinogenesis 2016, 37, 787-798. [CrossRef] [PubMed]

5. McCarroll, J.; Gan, P.P.; Erlich, R.B.; Liu, M.; Dwarte, T.; Sagnella, S.S.; Akerfeldt, M.C.; Yang, L.; Parker, A.L.; Chang, M.; et al. TUBB3/ $\beta$ III-Tubulin Acts through the PTEN/AKT Signaling Axis to Promote Tumorigenesis and Anoikis Resistance in Non-Small Cell Lung Cancer. Cancer Res. 2014, 75, 415-425. [CrossRef] [PubMed]

6. Janke, C.; Magiera, M.M. The tubulin code and its role in controlling microtubule properties and functions. Nat. Rev. Mol. Cell Biol. 2020, 21, 307-326. [CrossRef] [PubMed]

7. Carré, M.; André, N.; Carles, G.; Borghi, H.; Brichese, L.; Briand, C.; Braguer, D. Tubulin Is an Inherent Component of Mitochondrial Membranes That Interacts with the Voltage-dependent Anion Channel. J. Biol. Chem. 2002, 277, 33664-33669. [CrossRef] [PubMed]

8. Appaix, F.; Kuznetsov, A.V.; Usson, Y.; Kay, L.; Andrienko, T.; Olivares, J.; Kaambre, T.; Sikk, P.; Margreiter, R.; Saks, V. Possible Role of Cytoskeleton in Intracellular Arrangement and Regulation of Mitochondria. Exp. Physiol. 2003, 88, 175-190. [CrossRef]

9. Anesti, V.; Scorrano, L. The relationship between mitochondrial shape and function and the cytoskeleton. Biochim. Biophys. Acta 2006, 1757, 692-699. [CrossRef]

10. Pareyson, D.; Saveri, P.; Sagnelli, A.; Piscosquito, G. Mitochondrial dynamics and inherited peripheral nerve diseases. Neurosci. Lett. 2015, 596, 66-77. [CrossRef]

11. Ren, Y.; Jiang, H.; Yang, F.; Nakaso, K.; Feng, J. Parkin Protects Dopaminergic Neurons against Microtubule-depolymerizing Toxins by Attenuating Microtubule-associated Protein Kinase Activation. J. Biol. Chem. 2009, 284, 4009-4017. [CrossRef] [PubMed]

12. Ren, Y.; Zhao, J.; Feng, J. Parkin binds to alpha/beta tubulin and increases their ubiquitination and degradation. J. Neurosci. 2003, 23, 3316-3324. [CrossRef]

13. Silva, D.F.; Esteves, A.R.; Arduino, D.M.; Oliveira, C.R.; Cardoso, S.M. Amyloid- $\beta$-Induced Mitochondrial Dysfunction Impairs the Autophagic Lysosomal Pathway in a Tubulin Dependent Pathway. J. Alzheimer's Dis. 2011, 26, 565-581. [CrossRef] [PubMed]

14. Xie, R.; Wang, F.; McKeehan, W.L.; Liu, L. Autophagy Enhanced by Microtubule- and Mitochondrion-Associated MAP1S Suppresses Genome Instability and Hepatocarcinogenesis. Cancer Res. 2011, 71, 7537-7546. [CrossRef] [PubMed]

15. Lin, M.-Y.; Sheng, Z.-H. Regulation of mitochondrial transport in neurons. Exp. Cell Res. 2015, 334, 35-44. [CrossRef]

16. MacAskill, A.F.; Kittler, J.T. Control of mitochondrial transport and localization in neurons. Trends Cell Biol. 2010, $20,102-112$. [CrossRef] [PubMed] 
17. Sheng, Z.-H. Mitochondrial trafficking and anchoring in neurons: New insight and implications. J. Cell Biol. 2014, 204, 1087-1098. [CrossRef]

18. Vemu, A.; Atherton, J.; Spector, J.O.; Moores, C.A.; Roll-Mecak, A. Tubulin isoform composition tunes microtubule dynamics. Mol. Biol. Cell 2017, 28, 3564-3572. [CrossRef] [PubMed]

19. Honda, Y.; Tsuchiya, K.; Sumiyoshi, E.; Haruta, N.; Sugimoto, A. Tubulin isotype substitution revealed that isotype composition modulates microtubule dynamics in C. elegans embryos. J. Cell Sci. 2017, 130, 1652-1661. [CrossRef]

20. Zheng, P.; Obara, C.J.; Szczesna, E.; Nixon-Abell, J.; Mahalingan, K.K.; Roll-Mecak, A.; Lippincott-Schwartz, J.; Blackstone, C. ER proteins decipher the tubulin code to regulate organelle distribution. Nature 2021, 601, 132-138. [CrossRef]

21. Panda, D.; Miller, H.P.; Banerjee, A.; Luduena, R.F.; Wilson, L. Microtubule dynamics in vitro are regulated by the tubulin isotype composition. Proc. Natl. Acad. Sci. USA 1994, 91, 11358-11362. [CrossRef] [PubMed]

22. Kamath, K.; Wilson, L.; Cabral, F.; Jordan, M.A. ßIII-Tubulin Induces Paclitaxel Resistance in Association with Reduced Effects on Microtubule Dynamic Instability. J. Biol. Chem. 2005, 280, 12902-12907. [CrossRef] [PubMed]

23. Gan, P.P.; McCarroll, J.; Po'Uha, S.T.; Kamath, K.; Jordan, M.A.; Kavallaris, M. Microtubule Dynamics, Mitotic Arrest, and Apoptosis: Drug-Induced Differential Effects of $\beta$ III-Tubulin. Mol. Cancer Ther. 2010, 9, 1339-1348. [CrossRef]

24. Fu, C.; Jain, D.; Costa, J.; Velve-Casquillas, G.; Tran, P.T. mmb1p Binds Mitochondria to Dynamic Microtubules. Curr. Biol. 2011, 21, 1431-1439. [CrossRef]

25. Mehta, K.; Chacko, L.A.; Chug, M.K.; Jhunjhunwala, S.; Ananthanarayanan, V. Association of mitochondria with microtubules inhibits mitochondrial fission by precluding assembly of the fission protein Dnm1. J. Biol. Chem. 2019, 294, 3385-3396. [CrossRef] [PubMed]

26. Yaffe, M.P.; Stuurman, N.; Vale, R.D. Mitochondrial positioning in fission yeast is driven by association with dynamic microtubules and mitotic spindle poles. Proc. Natl. Acad. Sci. USA 2003, 100, 11424-11428. [CrossRef] [PubMed]

27. McVicker, D.P.; Chrin, L.R.; Berger, C.L. The Nucleotide-binding State of Microtubules Modulates Kinesin Processivity and the Ability of Tau to Inhibit Kinesin-mediated Transport. J. Biol. Chem. 2011, 286, 42873-42880. [CrossRef]

28. Feizabadi, M.S. The Contribution of the C-Terminal Tails of Microtubules in Altering the Force Production Specifications of Multiple Kinesin-1. Cell Biophys. 2016, 74, 373-380. [CrossRef] [PubMed]

29. Hirose, K.; Löwe, J.; Alonso, M.; Cross, R.; Amos, L. 3D Electron Microscopy of the Interaction of Kinesin with Tubulin. Cell Struct. Funct. 1999, 24, 277-284. [CrossRef]

30. Sirajuddin, M.; Rice, L.M.; Vale, R.D. Regulation of microtubule motors by tubulin isotypes and post-translational modifications Nat. Cell Biol. 2014, 16, 335-344. [CrossRef] [PubMed]

31. Tanaka, Y.; Kanai, Y.; Okada, Y.; Nonaka, S.; Takeda, S.; Harada, A.; Hirokawa, N. Targeted Disruption of Mouse Conventional Kinesin Heavy Chain kif5B, Results in Abnormal Perinuclear Clustering of Mitochondria. Cell 1998, 93, 1147-1158. [CrossRef]

32. Pilling, A.D.; Horiuchi, D.; Lively, C.M.; Saxton, W.M. Kinesin-1 and Dynein Are the Primary Motors for Fast Transport of Mitochondria inDrosophilaMotor Axons. Mol. Biol. Cell 2006, 17, 2057-2068. [CrossRef]

33. Rostovtseva, T.K.; Gurnev, P.A.; Hoogerheide, D.P.; Rovini, A.; Sirajuddin, M.; Bezrukov, S.M.; Rostovtseva, T.K.; Gurnev, P.A.; Hoogerheide, D.P.; Rovini, A.; et al. Sequence diversity of tubulin isotypes in regulation of the mitochondrial voltage-dependent anion channel. J. Biol. Chem. 2018, 293, 10949-10962. [CrossRef]

34. Rostovtseva, T.K.; Sheldon, K.L.; Hassanzadeh, E.; Monge, C.; Saks, V.; Bezrukov, S.M.; Sackett, D.L. Tubulin binding blocks mitochondrial voltage-dependent anion channel and regulates respiration. Proc. Natl. Acad. Sci. USA 2008, 105, 18746-18751. [CrossRef]

35. Sheldon, K.L.; Maldonado, E.N.; Lemasters, J.J.; Rostovtseva, T.K.; Bezrukov, S.M. Phosphorylation of Voltage-Dependent Anion Channel by Serine/Threonine Kinases Governs Its Interaction with Tubulin. PLoS ONE 2011, 6, e25539. [CrossRef] [PubMed]

36. Jung, D.; Filliol, D.; Miehe, M.; Rendón, A. Interaction of brain mitochondria with microtubules reconstituted from brain tubulin and MAP2 or TAU. Cell Motil. Cytoskelet. 1993, 24, 245-255. [CrossRef]

37. Cicchillitti, L.; Penci, R.; Di Michele, M.; Filippetti, F.; Rotilio, D.; Donati, M.B.; Scambia, G.; Ferlini, C. Proteomic characterization of cytoskeletal and mitochondrial class III $\beta$-tubulin. Mol. Cancer Ther. 2008, 7, 2070-2079. [CrossRef] [PubMed]

38. Rovini, A.; Savry, A.; Braguer, D.; Carré, M. Microtubule-targeted agents: When mitochondria become essential to chemotherapy. Biochim. et Biophys. Acta 2011, 1807, 679-688. [CrossRef]

39. Bernier-Valentin, F.; Aunis, D.; Rousset, B. Evidence for tubulin-binding sites on cellular membranes: Plasma membranes, mitochondrial membranes, and secretory granule membranes. J. Cell Biol. 1983, 97, 209-216. [CrossRef] [PubMed]

40. Tischfield, M.A.; Engle, E.C. Distinct $\alpha$ - and $\beta$-tubulin isotypes are required for the positioning, differentiation and survival of neurons: New support for the 'multi-tubulin' hypothesis. Biosci. Rep. 2010, 30, 319-330. [CrossRef] [PubMed]

41. Tischfield, M.A.; Baris, H.N.; Wu, C.; Rudolph, G.; Van Maldergem, L.; He, W.; Chan, W.-M.; Andrews, C.; Demer, J.L.; Robertson, R.L.; et al. Human TUBB3 Mutations Perturb Microtubule Dynamics, Kinesin Interactions, and Axon Guidance. Cell 2010, 140, 74-87. [CrossRef] [PubMed]

42. Chew, S.; Balasubramanian, R.; Chan, W.-M.; Kang, P.; Andrews, C.; Webb, B.D.; MacKinnon, S.E.; Oystreck, D.T.; Rankin, J.; Crawford, T.O.; et al. A novel syndrome caused by the E410K amino acid substitution in the neuronal $\beta$-tubulin isotype 3. Brain 2013, 136, 522-535. [CrossRef]

43. Niwa, S.; Takahashi, H.; Hirokawa, N. $\beta$-Tubulin mutations that cause severe neuropathies disrupt axonal transport. EMBO J. 2013, 32, 1352-1364. [CrossRef] [PubMed] 
44. McCarroll, J.A.; Gan, P.P.; Liu, M.; Kavallaris, M. ßIII-Tubulin Is a Multifunctional Protein Involved in Drug Sensitivity and Tumorigenesis in Non-Small Cell Lung Cancer. Cancer Res. 2010, 70, 4995-5003. [CrossRef] [PubMed]

45. Ariotti, N.; Wu, Y.; Okano, S.; Gambin, Y.; Follett, J.; Rae, J.; Ferguson, C.; Teasdale, R.D.; Alexandrov, K.; Meunier, F.A.; et al An inverted CAV1 (caveolin 1) topology defines novel autophagy-dependent exosome secretion from prostate cancer cells. Autophagy 2020, 17, 2200-2216. [CrossRef] [PubMed]

46. Takasato, M.; Er, P.X.; Chiu, H.S.; Maier, B.; Baillie, G.J.; Ferguson, C.; Parton, R.G.; Wolvetang, E.J.; Roost, M.S.; De Sousa, S.M.C.L.; et al. Kidney organoids from human iPS cells contain multiple lineages and model human nephrogenesis. Nature $\mathbf{2 0 1 5}$ 526, 564-568. [CrossRef] [PubMed]

47. Jaqaman, K.; Loerke, D.; Mettlen, M.; Kuwata, H.; Grinstein, S.; Schmid, S.; Danuser, G. Robust single-particle tracking in live-cell time-lapse sequences. Nat. Methods 2008, 5, 695-702. [CrossRef]

48. Gan, P.P.; Pasquier, E.; Kavallaris, M. Class III $\beta$-Tubulin Mediates Sensitivity to Chemotherapeutic Drugs in Non-Small Cell Lung Cancer. Cancer Res. 2007, 67, 9356-9363. [CrossRef]

49. Bhattacharyya, T.; Karnezis, A.N.; Murphy, S.P.; Hoang, T.; Freeman, B.C.; Phillips, B.; Morimoto, R.I. Cloning and Subcellular Localization of Human Mitochondrial hsp70. J. Biol. Chem. 1995, 270, 1705-1710. [CrossRef]

50. Ouellet, M.; Guillebaud, G.; Gervais, V.; St-Pierre, D.L.; Germain, M. A novel algorithm identifies stress-induced alterations in mitochondrial connectivity and inner membrane structure from confocal images. PLOS Comput. Biol. 2017, 13, e1005612. [CrossRef]

51. Lemasters, J.J.; Qian, T.; He, L.; Kim, J.-S.; Elmore, S.P.; Cascio, W.E.; Brenner, D. Role of Mitochondrial Inner Membrane Permeabilization in Necrotic Cell Death, Apoptosis, and Autophagy. Antioxidants Redox Signal. 2002, 4, 769-781. [CrossRef]

52. Rossignol, R.; Gilkerson, R.; Aggeler, R.; Yamagata, K.; Remington, S.J.; Capaldi, R.A. Energy Substrate Modulates Mitochondrial Structure and Oxidative Capacity in Cancer Cells. Cancer Res. 2004, 64, 985-993. [CrossRef] [PubMed]

53. Gomes, L.C.; Di Benedetto, G.; Scorrano, L. During autophagy mitochondria elongate, are spared from degradation and sustain cell viability. Nat. Cell Biol. 2011, 13, 589-598. [CrossRef] [PubMed]

54. Rambold, A.S.; Kostelecky, B.; Elia, N.; Lippincott-Schwartz, J. Tubular network formation protects mitochondria from autophagosomal degradation during nutrient starvation. Proc. Natl. Acad. Sci. USA 2011, 108, 10190-10195. [CrossRef] [PubMed]

55. Liu, Y.; Ma, X.; Fujioka, H.; Liu, J.; Chen, S.; Zhu, X. DJ-1 regulates the integrity and function of ER-mitochondria association through interaction with IP3R3-Grp75-VDAC1. Proc. Natl. Acad. Sci. USA 2019, 116, 25322-25328. [CrossRef]

56. Canet-Avilés, R.M.; Wilson, M.A.; Miller, D.W.; Ahmad, R.; McLendon, C.; Bandyopadhyay, S.; Baptista, M.J.; Ringe, D.; Petsko, G.A.; Cookson, M.R. The Parkinson's disease protein DJ-1 is neuroprotective due to cysteine-sulfinic acid-driven mitochondrial localization. Proc. Natl. Acad. Sci. USA 2004, 101, 9103-9108. [CrossRef] [PubMed]

57. McCarroll, J.A.; Sharbeen, G.; Liu, J.; Youkhana, J.; Goldstein, D.; McCarthy, N.; Limbri, L.F.; Dischl, D.; Ceyhan, G.O.; Erkan, M.; et al. beta III-Tubulin: A novel mediator of chemoresistance and metastases in pan-creatic cancer. Oncotarget 2015, 6, 2235-2249. [CrossRef]

58. Al-Mehdi, A.-B.; Pastukh, V.M.; Swiger, B.M.; Reed, D.J.; Patel, M.R.; Bardwell, G.C.; Pastukh, V.V.; Alexeyev, M.F.; Gillespie, M.N. Perinuclear Mitochondrial Clustering Creates an Oxidant-Rich Nuclear Domain Required for Hypoxia-Induced Transcription. Sci. Signal. 2012, 5, ra47. [CrossRef]

59. Strohecker, A.M.; Guo, J.Y.; Karsli-Uzunbas, G.; Price, S.M.; Chen, G.J.; Mathew, R.; McMahon, M.; White, E. Autophagy Sustains Mitochondrial Glutamine Metabolism and Growth of BrafV600E-Driven Lung Tumors. Cancer Discov. 2013, 3, $1272-1285$. [CrossRef]

60. Karsli-Uzunbas, G.; Guo, J.Y.; Price, S.; Teng, X.; Laddha, S.V.; Khor, S.; Kalaany, N.Y.; Jacks, T.; Chan, C.S.; Rabinowitz, J.D.; et al. Autophagy Is Required for Glucose Homeostasis and Lung Tumor Maintenance. Cancer Discov. 2014, 4, 914-927. [CrossRef]

61. Caino, M.C.; Altieri, D.C. Cancer cells exploit adaptive mitochondrial dynamics to increase tumor cell invasion. Cell Cycle 2015, 14, 3242-3247. [CrossRef]

62. Zala, D.; Hinckelmann, M.-V.; Yu, H.; Lyra Da Cunha, M.M.; Liot, G.; Cordelières, F.P.; Marco, S.; Saudou, F. Vesicular Glycolysis Provides On-Board Energy for Fast Axonal Transport. Cell 2013, 152, 479-491. [CrossRef]

63. Parrado-Fernández, C.; Schreiner, B.; Ankarcrona, M.; Conti, M.M.; Cookson, M.R.; Kivipelto, M.; Cedazo-Minguez, A.; Sandebring-Matton, A. Reduction of PINK1 or DJ-1 impair mitochondrial motility in neurites and alter ER-mitochondria contacts. J. Cell. Mol. Med. 2018, 22, 5439-5449. [CrossRef] [PubMed]

64. Sheng, C.; Heng, X.; Zhang, G.; Xiong, R.; Li, H.; Zhang, S.; Chen, S. DJ-1 deficiency perturbs microtubule dynamics and impairs striatal neurite outgrowth. Neurobiol. Aging 2013, 34, 489-498. [CrossRef] [PubMed]

65. Maldonado, E.N.; Sheldon, K.L.; DeHart, D.N.; Patnaik, J.; Manevich, Y.; Townsend, D.M.; Bezrukov, S.M.; Rostovtseva, T.K.; Lemasters, J.J. Voltage-dependent Anion Channels Modulate Mitochondrial Metabolism in Cancer Cells. J. Biol. Chem. 2013, 288, 11920-11929. [CrossRef]

66. Guzun, R.; Karu-Varikmaa, M.; Gonzalez-Granillo, M.; Kuznetsov, A.V.; Michel, L.; Cottet-Rousselle, C.; Saaremäe, M.; Kaambre, T.; Metsis, M.; Grimm, M.; et al. Mitochondria-cytoskeleton interaction: Distribution of $\beta$-tubulins in cardiomyocytes and HL-1 cells. Biochim. Biophys. Acta 2011, 1807, 458-469. [CrossRef] [PubMed]

67. Gonzalez-Granillo, M.; Grichine, A.; Guzun, R.; Usson, Y.; Tepp, K.; Chekulayev, V.; Shevchuk, I.; Karu-Varikmaa, M.; Kuznetsov, A.V.; Grimm, M.; et al. Studies of the role of tubulin beta II isotype in regulation of mitochondrial respiration in intracellular energetic units in cardiac cells. J. Mol. Cell. Cardiol. 2012, 52, 437-447. [CrossRef] [PubMed] 
68. Varikmaa, M.; Bagur, R.; Kaambre, T.; Grichine, A.; Timohhina, N.; Tepp, K.; Shevchuk, I.; Chekulayev, V.; Metsis, M.; Boucher, F.; et al. Role of mitochondria-cytoskeleton interactions in respiration regulation and mitochondrial organization in striated muscles. Biochim. Biophys. Acta 2014, 1837, 232-245. [CrossRef]

69. Vulinovic, F.; Krajka, V.; Hausrat, T.J.; Seibler, P.; Alvarez-Fischer, D.; Madoev, H.; Park, J.-S.; Kumar, K.R.; Sue, C.M.; Lohmann, K.; et al. Motor protein binding and mitochondrial transport are altered by pathogenic TUBB4A variants. Hum. Mutat. 2018, 39, 1901-1915. [CrossRef]

70. Rezania, V.; Azarenko, O.; Jordan, M.A.; Bolterauer, H.; Ludueña, R.F.; Huzil, J.T.; Tuszynski, J.A. Microtubule Assembly of Isotypically Purified Tubulin and Its Mixtures. Biophys. J. 2008, 95, 1993-2008. [CrossRef] 